\title{
Influence of Spatial Variation in Sap Flux Density on Estimates of Whole-tree Water Use in Avicennia marina
}

\author{
B.A.E. Van de $\mathrm{Wal}^{1}$, A. Guyot ${ }^{2,3}$, C.E. Lovelock ${ }^{2,4}$, D.A. Lockington ${ }^{2,3}$ and K. Steppe ${ }^{1}$ \\ ${ }^{1}$ Laboratory of Plant Ecology, Faculty of Bioscience Engineering, Ghent University, \\ Ghent, Belgium \\ ${ }^{2}$ Nat. Centre for Groundwater Research and Training School of the Environment, \\ Flinders University, Adelaide, SA, Australia \\ ${ }^{3}$ School of Civil Engineering, The University of Queensland, St. Lucia 4072, Brisbane, \\ Queensland, Australia \\ ${ }^{4}$ School of Biological Sciences, The University of Queensland, St. Lucia 4072, Brisbane, \\ Queensland, Australia
}

Keywords: Sap flow, Avicennia marina, HFD, HRM, whole-plant water use, azimuthal and radial variation

\begin{abstract}
Sap flux density measurements are used worldwide as a relatively inexpensive means to provide an estimate of whole-tree and whole-stand water use in forest ecosystems. However, erroneous up-scaling from point measurements to the entire sapwood area remains an important issue, since sap flux density is hardly ever constant throughout the cross-section of a tree. In this study, two widely used sap flow methodologies (the Heat Ratio Method or HRM and the Heat Field Deformation method or HFD) are used to assess radial and azimuthal variations in sap flux density in the mangrove species Avicennia marina or grey mangrove, a species that is characterised by a secondary growth via successive cambia, resulting in an atypical sapwood pattern of xylem patches braided with phloem strings.

Sap flux density values were scaled up to whole-tree water use in different ways. Initial estimates of sap flux were made from point measurements, ignoring spatial variations. We then adjusted these measurements by including radial and azimuthal variations assessed by measurements of radial profiles and multiple sensors around the circumference of the tree, respectively.

Our results showed a discrepancy of $237 \pm 26 \%$ between the lowest and highest water use estimate, as a consequence of the high radial and azimuthal variations in sap flux density in this species. Our study indicates that caution is required when interpreting sap flux density values, hence it is crucial to account for radial and azimuthal variation when scaling up from point measurements to wholetree water use.
\end{abstract}

\section{INTRODUCTION}

Sap flow sensors are used worldwide to estimate whole-tree and even wholeecosystem water use (Steppe et al., 2009). The reason for this is that they are relatively inexpensive and user friendly in comparison to other techniques such as whole-tree potometers or weighing lysimeter (Wullschleger et al., 1998). On the downside, most sap flow sensors provide only one or a few measurement points throughout the tree where sap flux density is measured. This can lead to erroneous up-scaling of measurements to whole-tree water use, since there can be significant fluctuations, both radial and azimuthal, in sap flux density (Cohen et al., 2012). 
Multiple studies have tried to account for the radial profile in sap flux density in woody plants, most of which concluding that sap flux density reaches a maximum close to the bark and declines towards the center of the tree (Wullschleger and King, 2000). This concurs with the hypothesis that newly formed vascular tissue, which emanates from the vascular cambium, has a higher hydraulic conductivity than older parts of the sapwood (Phillips et al., 1996).

In contrast to most woody plants, the mangrove genus Avicennia has a secondary growth through a reticulate structure of multiple vascular cambia, resulting in a three dimensional network of secondary xylem patches braided with strings of secondary phloem as shown in Fig. 1 (Robert et al., 2011). Therefore, radial and azimuthal variations in sap flow are likely to be even greater and less predictable, making it an interesting genus to demonstrate flaws in up-scaling from point measurements to wholetree water use.

Of the few studies on water use in Avicennia, only one accounts for the radial profile in sap flux density (Krauss et al., 2007), and none account for possible azimuthal fluctuations (Becker et al., 1997; Muller et al., 2009). Hence, in this study, we will try to assess these differences by installing multiple sap flow sensors on a single tree of the species Avicennia marina.

\section{MATERIALS AND METHODS}

The experiment was conducted in a mangrove forest patch on the bank of the Brisbane River (Brisbane, Queensland, Australia; 27 $30^{\prime} \mathrm{S}-153^{\circ} 01^{\prime} \mathrm{E}$ ). The site has semidiurnal tides and soil salinity that fluctuates between $5 \mathrm{ppt}$ in the wet season and 20 ppt in the dry season. Avicennia marina trees, reaching up to $20 \mathrm{~m}$ with an understory of small Aegiceras corniculatum shrubs, dominate the site.

\section{Sap Flow Measurements}

One Avicennia marina tree (290mm DBH) was equipped with a total of four sap flow sensors (ICT International PTY LTD, Armidale, NSW, Australia) for a period of two months in 2010 (September $7^{\text {th }}$ to November $9^{\text {th }}$, DOY 250-313). Two of these sensors were of the Heat Ratio Method (HRM) type as described by Burgess et al. (2001) and the other two of the Heat Field Deformation method (HFD) type as described by Nadezhdina et al. (2012). The HFD sensors provide 8 measurement points throughout the tree (ranging from 5 to $75 \mathrm{~mm}$ depth with a spacing of $10 \mathrm{~mm}$ between them) whereas the HRM sensors only provide one measurement point at a depth of $22.5 \mathrm{~mm}$. From both types, one sensor was installed at breast height on the north side of the tree, and one sensor on the south side. To avoid interference between sensors, a horizontal distance of $100 \mathrm{~mm}$ was respected between sensors installed on the same side.

\section{Sapwood Depth}

To estimate the sapwood depth, toluidine blue dye was injected into the stem before sunrise (5:00 AM) both on the north and south side, and wood cores were taken from the stem just above the injection site at midday (11:00 AM). The stained part of the wood core then represents the living sapwood, whereas the unstained part represents the heartwood (Mencuccini and Grace, 1994). 


\section{Whole-tree Water Use Calculations}

Sap flux density measurements were scaled up to whole-tree water use based on three approaches in order to assess the influence of the sensor setup and the radial and azimuthal variations of sap flow in the tree: (i) The first approach considers each sensor individually, resulting in four different estimations of the whole-tree water use; (ii) The second approach assigned to each sensor their respective half of the tree, resulting in one estimation of the whole tree water use with the HRM sensors and one with the HFD sensors; (iii) Finally, the third approach combines the strength of information of both methodologies, by correcting the radial profiles of the HFD with point measurements of the HRM sensors.

\section{RESULTS AND DISCUSSION}

\section{Sap Wood Depth}

The wood cores taken from the tree after the toluidine blue dye injection showed a coloration up to a depth of $50 \mathrm{~mm}$ on the south side of the tree and up to $74 \mathrm{~mm}$ on the north side of the tree. These values were each assigned to their respective half of the tree and used to calculate water use based on the HRM sensors only. Radial sap flow profiles obtained with HFD sensors (Fig. 2) however showed that high sap flows were present beyond $50 \mathrm{~mm}$ on the south side of the tree, yet sap flow on the north side was close to zero at $75 \mathrm{~mm}$, which corresponds with the observed sapwood depth. Since no information is available beyond $75 \mathrm{~mm}$, this was assumed to be the sapwood depth for calculations using the HFD sensors.

\section{Whole-tree Water Use}

Whole-tree water use differed substantially between the different calculations, leading to a difference of $237 \pm 26 \%$ between the highest and lowest estimation. Based on HFD measurements, mean daily water use was $12.4 \pm 0.5 \mathrm{~L} \mathrm{~d}^{-1}$, while HRM sensors led to a water use of $18 \pm 1 \mathrm{~L} \mathrm{~d}^{-1}$. When radial profiles obtained with the HFD sensors were scaled up using the HRM point measurements, mean daily whole-tree water use was $21.2 \pm 1.5 \mathrm{~L} \mathrm{~d}^{-1}$.

This high variability can be attributed to three different causes: the radial and azimuthal variations in sap flux density and the accuracy of the sensor.

1. Azimuthal Variability in Sap Flow. Sap flux density measurements differed greatly between the two sides of the tree. Water use based on the corrected HFD profiles showed that water use on the southern side was $108 \pm 18 \%$ greater than on the northern side, as shown in Fig. 3.

A possible explanation for this discrepancy may be due to variation in the morphology of the tree. The vascular tissue connected to the most transpiring parts of the canopy will show the highest sap flux densities (Saveyn et al., 2008). This aspect is not easily predicted, since transpiration rates depend on multiple factors, such as number of leaves, leaf area, exposure to wind, light availability etc., making pure visual inspection possibly misleading. Furthermore, the water uptake pathway might not be straightforward, meaning that the vascular tissue at one side of the stem at breast height is not necessarily connected to the canopy at the same side of the tree. For example, in our experimental tree, there are two major branches, but the data showed higher sap flux densities on the same side as the smallest of these two branches. A more profound knowledge of the tree 
morphology and the interactions with its surroundings (e.g. shaded vs. unshaded parts) is hence needed to assess this azimuthal variability.

2. Radial Variability in Sap Flow. Radial profiles as shown in Fig. 2 demonstrate that there is a high radial variability in sap flux density. This radial variability is far from predictable, given the difference between the two profiles. The northern profile shows a typical declining pattern towards the centre of the stem, as is also observed by Krauss et al. (2007), which is highly contrasting with the southern profile, which shows a peak at a depth of $55 \mathrm{~mm}$. This underlines the unpredictability of the radial profile, which was to be expected given the unusual xylem structure of Avicennia marina.

While it is sometimes suggested that a correction based on a single radial profile can be used for up-scaling point measurements to whole-tree water use since radial profiles are fairly uniform throughout the tree (Lu et al., 2000; Delzon et al., 2004), our results clearly show that it is crucial to measure multiple radial profiles when estimating water use in Avicennia or other species with irregular wood structure.

3. Sensor Discrepancy. Sap flux density values from the HRM sensor were $58 \pm 14 \%$ and $120 \pm 50 \%$ higher than the HFD values for the north and south side of the tree respectively (an interpolation of the HFD values at $15 \mathrm{~mm}$ and $25 \mathrm{~mm}$ depth was made to the depth of the HRM sensor, i.e. at $22.5 \mathrm{~mm}$ ). This difference is most likely due to the known underestimation of sap flux densities by the HFD method, as described by Steppe et al. (2010) in contrast to the accurate values obtained with the HRM when installed correctly (Bleby et al., 2004; Madurapperuma et al., 2009). Furthermore, since sensors are not located at the exact same position, the azimuthal variation in sap flux density is likely to have a significant effect on this discrepancy as well.

\section{CONCLUSIONS}

Our results indicated that up-scaling sap flux density values to whole-tree water use requires consideration of variation in sap flux throughout the tree. First of all, radial variability cannot be neglected, since this can result in over- or underestimations, depending on the depth of the measurement point. Furthermore, this radial variability is highly unpredictable in Avicennia marina, and possibly other species, due to its exceptional wood structure. In order to account for variation we recommend measuring sap flux in multiple radial profiles around the stem to avoid misinterpretations.

A second important source of possible errors, the azimuthal variation of sap flow, is equally hard to predict, since it is influenced by multiple morphological and environmental parameters, making external traits of the tree possibly misleading. Hence, this issue should also be tackled by installing multiple sensors around the circumference of the stem.

Last but not least, sensor choice is highly important to avoid over and underestimates. HFD sensors are very useful since they provide a radial sap flux density profile throughout the sapwood, which is crucial for whole-tree water use estimates, however underestimation of actual sap flux density is problematic. This issue can be tackled by adopting the newly developed empirical methodology for this sensor, which needs a plant specific calibration (Vandegehuchte and Steppe, 2012), or by combining the radial profile of the HFD with more accurate point measurements. 


\section{ACKNOWLEDGEMENTS}

The authors thank the Agency for Innovation by Science and Technology in Flanders (IWT) for the PhD funding granted to the first author, the Scientific Research Committee (CWO), Faculty of Bioscience Engineering, Ghent University, Belgium, for the travel grant, allowing a research stay at the University of Queensland and ICT International, Armidale, NSW, Australia for technical support with the equipment.

\section{Literature Cited}

Becker, P., Asmat, A., Mohamad, J., Moksin, M. and Tyree, M. T. 1997. Sap flow rates of mangrove trees are not unusually low. Trees-Struct. Funct. 11:432-435.

Bleby, T. M., Burgess, S. S. O. and Adams, M. A. 2004. A validation, comparison and error analysis of two heat-pulse methods for measuring sap flow in Eucalyptus marginata saplings. Funct. Plant Biol. 31:645-658.

Burgess, S. S. O., Adams, M. A., Turner, N. C., Beverly, C. R., Ong, C. K., Khan, A. A. H. and Bleby, T. M. 2001. An improved heat pulse method to measure low and reverse rates of sap flow in woody plants. Tree Physiol. 21:589-598.

Cohen, S., Wheeler, J. and Holbrook, N. M. 2012. The Radial and Azimuthal (or Tangential) Distribution of Sap Velocity in Tree Stems - Why and Can We Predict It? p. 131-137. In: L. Sebastiani, R. Tognetti, and A. Motisi (eds.), VIII International Symposium on Sap Flow, Vol. 951, Acta Hort. Int Soc Horticultural Science, Leuven

Delzon, S., Sartore, M., Granier, A. and Loustau, D. 2004. Radial profiles of sap flow with increasing tree size in maritime pine. Tree Physiol. 24:1285-1293.

Krauss, K. W., Young, P. J., Chambers, J. L., Doyle, T. W. and Twilley, R. R. 2007. Sap flow characteristics of neotropical mangroves in flooded and drained soils. Tree Physiol. 27:775-783.

Lu, P., Muller, W. J. and Chacko, E. K. 2000. Spatial variations in xylem sap flux density in the trunk of orchard-grown, mature mango trees under changing soil water conditions. Tree Physiol. 20:683-692.

Madurapperuma, W. S., Bleby, T. M. and Burgess, S. S. O. 2009. Evaluation of sap flow methods to determine water use by cultivated palms. Environ. Exp. Bot. 66:372-380.

Mencuccini, M. and Grace, J. 1995. Climate influences the leaf-area sapwood area ratio in Scots pine. Tree Physiol. 15:1-10.

Muller, E., Lambs, L. and Fromard, F. 2009. Variations in water use by a mature mangrove of Avicennia germinans, French Guiana. Ann. For. Sci. 66.

Nadezhdina, N., Vandegehuchte, M. W. and Steppe, K. 2012. Sap flux density measurements based on the heat field deformation method. Trees-Struct. Funct. 26:1439-1448.

Phillips, N., Oren, R. and Zimmermann, R. 1996. Radial patterns of xylem sap flow in non-, diffuse- and ring-porous tree species. Plant Cell Environ. 19:983-990.

Robert, E. M. R., Schmitz, N., Boeren, I., Driessens, T., Herremans, K., De Mey, J., Van de Casteele, E., Beeckman, H. and Koedam, N. 2011. Successive Cambia: A Developmental Oddity or an Adaptive Structure? PLoS One 6.

Saveyn, A., Steppe, K. and Lemeur, R. 2008. Spatial variability of xylem sap flow in mature beech (Fagus sylvatica) and its diurnal dynamics in relation to microclimate. Botany 86:1440-1448.

Schmitz, N., Robert, E. M. R., Verheyden, A., Kairo, J. G., Beeckman, H. and Koedam, N. 2008. A patchy growth via successive and simultaneous cambia: Key to success of the most widespread mangrove species Avicennia marina? Ann. Bot. 101:49-58. 
Steppe, K., De Pauw, D. J. W., Doody, T. M. and Teskey, R. O. 2010. A comparison of sap flux density using thermal dissipation, heat pulse velocity and heat field deformation methods. Agr. Forest Meteorol. 150:1046-1056.

Steppe, K., De Pauw, D. J. W., Saveyn, A., Tahon, P., Nadezhdina, N., Cermak, J. and Lemeur, R. 2009. Radial Sap Flux Profiles and Beyond: an Easy Software Analysis Tool. p. 85-91. In: E. Fernandez and A. DiazEspejo (eds.), Vii International Workshop on Sap Flow, Vol. 846, Acta Hort.. Int Soc Horticultural Science, Leuven.

Vandegehuchte, M. W. and Steppe, K. 2012. Interpreting the Heat Field Deformation method: Erroneous use of thermal diffusivity and improved correlation between temperature ratio and sap flux density. Agr. Forest Meteorol. 162:91-97.

Wullschleger, S. D. and King, A. W. 2000. Radial variation in sap velocity as a function of stem diameter and sapwood thickness in yellow-poplar trees. Tree Physiol. 20:511518.

Wullschleger, S. D., Meinzer, F. C. and Vertessy, R. A. 1998. A review of whole-plant water use studies in trees. Tree Physiol. 18:499-512.

\section{Figures}

(a)

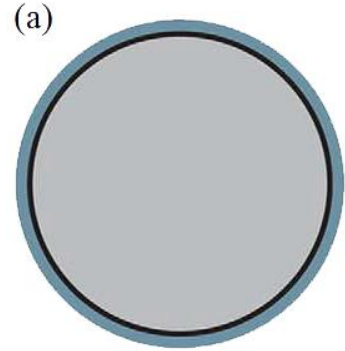

one cambium

$>$ stem: xylem tissue

$>$ bark: phloem tissue

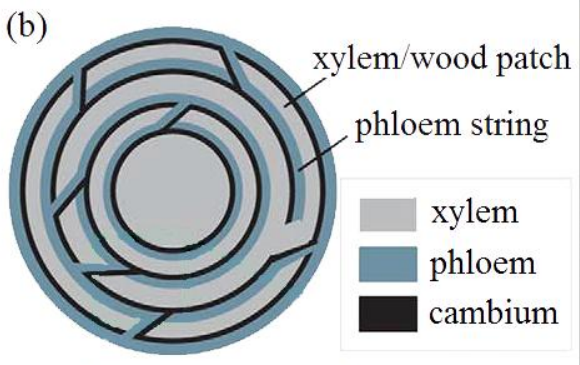

reticulate successive cambia

$>$ reticulate xylem structure

$>$ reticulate phloem structure



Fig. 1. Schematic representation of (a) a normal tree with only one cambium, (b) Avicennia with its network of successive cambia (Robert et al., 2011) and (c) a CT scan of the transverse plane in Avicennia marina, showing this reticulate structure (Schmitz et al., 2008). 


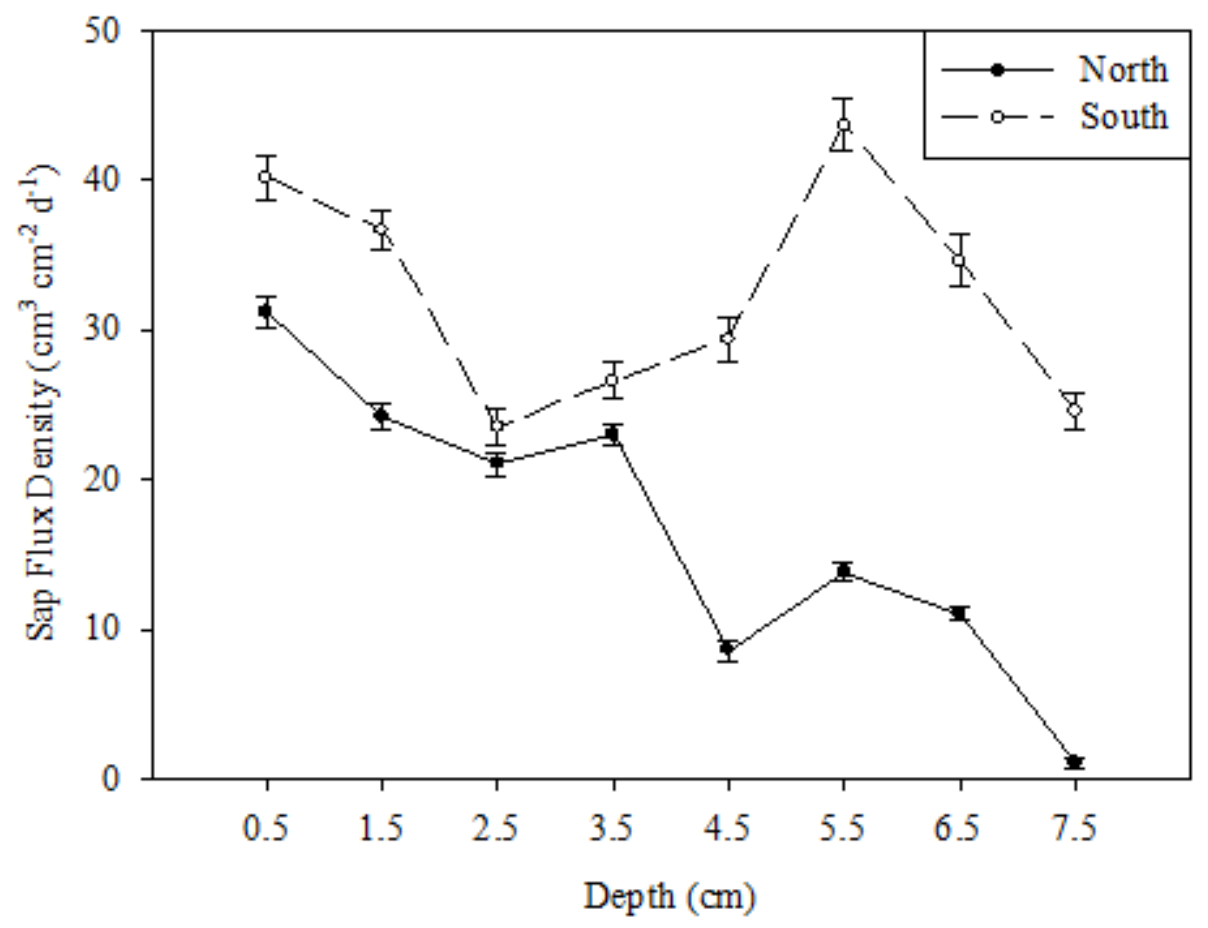

Fig. 2. Radial sap flux density profile for the two HFD sensors. Depth is measured from the outside of the bark. Sap flux density values are cumulated daily values $( \pm$ SE).

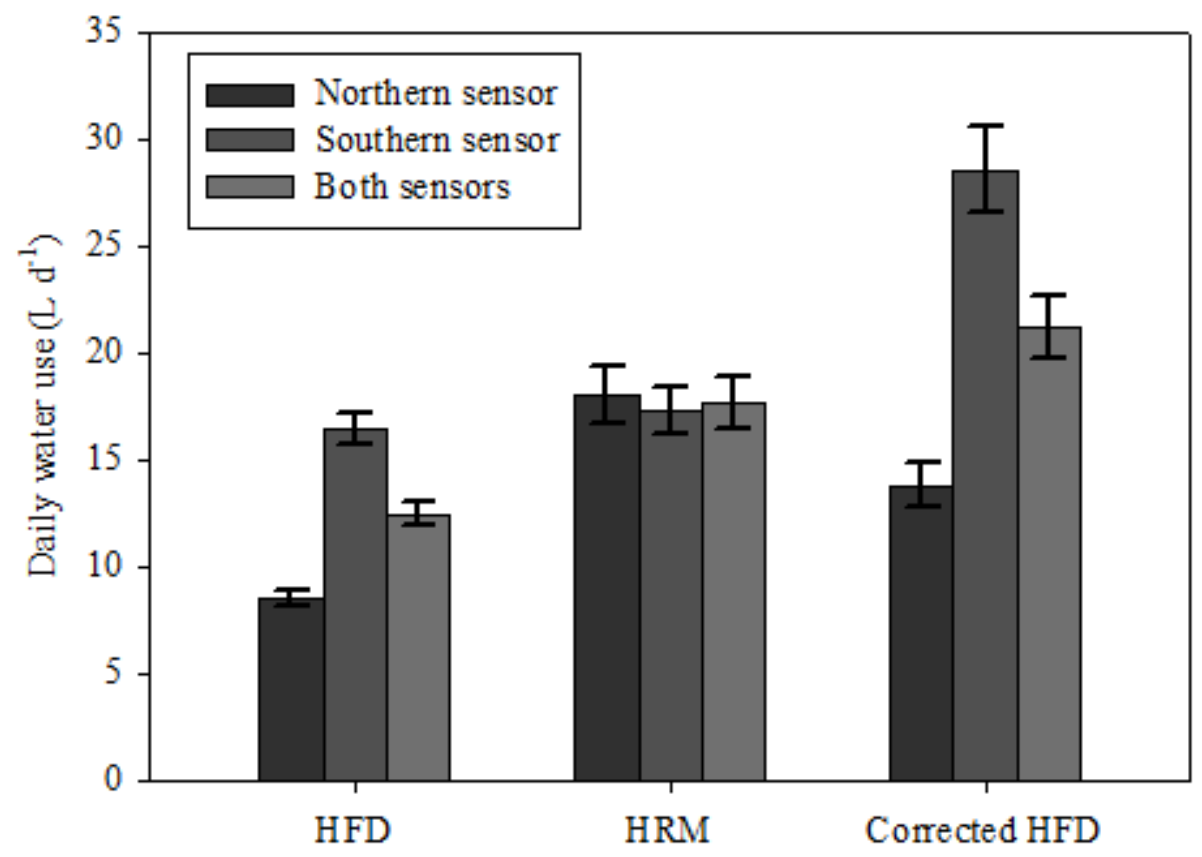

Fig. 3. Mean daily water use $( \pm \mathrm{SE})$, based on the different calculation methods, calculated over the whole time span of the experiment. 